\title{
Interactive comment on "SHORT COMMUNICATION: Massive Erosion in Monsoonal Central India Linked to Late Holocene Landcover Degradation” by Liviu Giosan et al.
}

\section{Liviu Giosan et al.}

Igiosan@whoi.edu

Received and published: 27 September 2017

Response: We thank the referee (P. Plink-Bjorklund) for her comment and share her enthusiasm on the important role of precipitation variability/seasonality and vegetation cover in river erosion.

Referee: This paper discusses two key aspects of erosion. One being the role of sealevel fall and the second climate control. The former has long been considered a key control on river erosion, due to the early models of Fisk (1944), further applied and promoted by sequence stratigraphic models, where erosion is linked to sea level fall and the river valleys are later filled during succeeding transgression (e.g. Posamentier and 
Vail, 1988; Posamentier et al., 1988; Van Wagoner et al., 1988, 1990; see discussion in Blum et al., 2013). More recent work exposes significant problems with this concept, as this concept ignores the role of drainage basin in erosion and sediment production and only considers the sediment produced by valley excavation. The concept also ignores other mechanisms of river erosion and causes for increased sediment production, as well as the backwater effects (see discussion in Blum et al., 2013; see also Lamb et al., 2012). Furthermore, where dated in great detail, the erosional river valley fills have been shown to contain falling stage, lowstand as well as transgressive deposits, as erosion and deposition are not mutually evasive processes and rather coincide spatially (see further review by Blum et al., 2013). What concerns climate control on erosion, then it is commonly referred to as a simple function of average annual rainfall, thus ignoring the effects of hydrological connectivity (such as the type of vegetation; e.g. Molnar, 2001; DiBiase and Whipple, 2011), as well as of the precipitation pattern (Leier et al., 2015; Plink-Bjorklund, 2015). High precipitation variability or seasonality, such as in monsoon conditions, causes surface water supply variability and focuses water and sediment discharge events to the wet seasons, such as in case of the Godavari. Thus, without increasing the annual average precipitation the water power and sediment transport capacity are increased in such river regimes. Increased aridity leads to reduced vegetation cover, but also may lead to increased rainfall intensity and thus flood intensity, thus increasing river's ability to erode (see review by Plink-Bjorklund, 2015). This manuscript is a significant contribution as a well documented example to signify the role of precipitation variability/seasonality and hydrological connectivity (vegetation cover) in river erosion. It promotes further discussion and data collection for both of the common assumptions what concerns river erosion. The manuscript is clearly written and there are no grammatical issues. The only issue I have is with a sentence that references Blum and Hattier-Womack (2009), as is it makes it sound like the referenced paper simply supports the notion of sea-level control on river erosion, whereas it actually promotes the role of climate in river erosion.

Response: We clarified our reference to Blum and Hattier-Womack (2009) as follows:

2

\section{ESurfD}

Interactive comment
Printer-friendly version

Discussion paper 
"Such complex variability did not inevitably follow the sea level cyclicity (e.g., Goodbred and Kuehl, 2000), which is usually assumed to control most of the sediment transfer ESurfD from land to the deep ocean (see Blum and Hattier-Womack, 2009 and references therein for an analysis underlining the increased recognition for climate role)."

Interactive comment on Earth Surf. Dynam. Discuss., https://doi.org/10.5194/esurf-2017-35, Interactive comment 2017. 